\title{
Keynote presentation
}

\section{$001 \mathrm{KP}$ PATIENT AND PUBLIC INVOLVEMENT IN RESEARCH: TENSIONS, CHALLENGES AND OPPORTUNITIES}

J Tritter. School of Languages and Social Sciences, Aston University, Birmingham, UK

10.1136/bmjopen-2017-016492.10

Increasingly research funders call for greater involvement of patients and the public in all aspects of research; an agenda that is even more prominent for public funding bodies. This agenda has been linked to a growing recognition of the relevance of patient experience in developing health services and patientcentred care and shared decision-making in clinical consultations. In this paper I explore the conceptual challenges in defining patient involvement and public involvement and the implications this has for public legitimacy in shaping research agendas and the research process. Patients have a different, and typically individual stake in research while members of the public as policy agents can enact a more collectivist orientation. Collaborative research is premised on different forms of expertise but is often framed as a contestation between different types of knowledge often reflecting the zero-sum model of decision making power that underpins Arnstein's Ladder of Citizen Participation. Such an approach fails to consider that members of a research team typically have different roles and responsibilities and that this does not necessarily diminish the collaboration. I conclude with reflections on how partnership in research should be based on the recognition of difference rather than equal roles and responsibilities. Such an approach, I argue may enhance rather than compromise research collaboration between academics, service users and members of the public. 